\title{
The SYNTAX battle in the war between stent and bypass: A landmark surgical win
}

\author{
Saswata Deb, MD, and Stephen E. Fremes, MD
}

\footnotetext{
From the Schulich Heart Centre, Sunnybrook Health Sciences Centre and the Toronto Ontario Institute of Health Policy Management and Evaluation, University of Toronto, Toronto, Ontario, Canada. Disclosures: Authors have nothing to disclose with regard to commercial support.

Received for publication July 12, 2016; accepted for publication July 18, 2016; available ahead of print Aug 24 , 2016.

Address for reprints: Stephen E. Fremes, MD, University of Toronto, Schulich Heart Centre, Sunnybrook Health Sciences Centre, 2075 Bayview Ave, Room H405, Toronto, Ontario, Canada M4N 3M5 (E-mail: stephen. fremes@sunnybrook.ca).

J Thorac Cardiovasc Surg 2016;152:1241-2

$0022-5223 / \$ 36.00$

Copyright (c) 2016 by The American Association for Thoracic Surgery

http://dx.doi.org/10.1016/j.jtcvs.2016.07.029
}

The long-standing debate as to which coronary artery revascularization treatment modality (percutaneous coronary intervention [PCI] or coronary artery bypass grafting $[\mathrm{CABG}])$ is superior continues to evolve. The largest comprehensive trial performed to date in this topic has been the Synergy Between PCI With Taxus and Cardiac Surgery [SYNTAX] trial. ${ }^{1,2}$ There have been many published secondary analyses from this trial, ${ }^{3,4}$ with the most recent being a 5-year analysis of causes of death after PCI or CABG. ${ }^{5}$ This study showed a higher incidence of cardiac-related death (mainly due to myocardial infarction) among patients with complex coronary disease who underwent PCI compared with those who underwent CABG. To this end, Mack and colleagues ${ }^{6}$ have provided an Expert Opinion article in this issue of the Journal summarizing and highlighting the key findings of the SYNTAX subanalysis.

Mack and colleagues ${ }^{6}$ have nicely summarized the key methods of the SYNTAX trial while raising some important points regarding $\mathrm{CABG}$ and PCI. One explanation of possible better outcomes associated with CABG relative to PCI in this study is incomplete revascularization (IR). IR was present in $43.3 \%$ of patients who underwent PCI and $36.8 \%$ of patients who underwent CABG and was an independent predictor for the overall randomized cohort as a risk factor of cardiac mortality. It has been shown that IR is associated with worse long-term survival among patients undergoing multivessel $\mathrm{PCI}^{7}$ and also among those undergoing $\mathrm{CABG}{ }^{8}$ A meta-analysis of randomized, controlled trials including 89,883 patients $^{9}$ who underwent PCI or CABG comparing IR versus complete revascularization concluded that complete revascularization is achieved more commonly with CABG than with PCI and that complete revascularization was associated with lower longterm mortality irrespective of modality $(\mathrm{CABG}$ relative risk, 0.70; $P<.001$; PCI relative risk, 0.72; $P<.001)$.

It is also worth noting that another study of 2686 patients assessed residual SYNTAX score (rSS), a surrogate mortality. $^{10}$

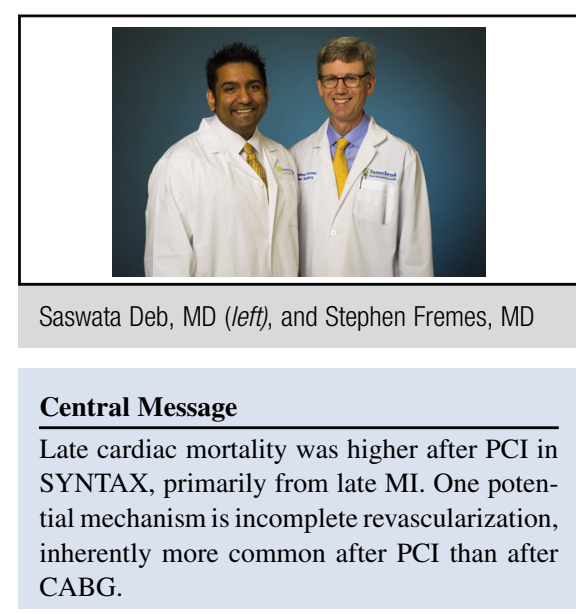

See Article page 1237.

quantitative marker of IR, in patients who underwent PCI. ${ }^{10}$ They reported a strong correlation between baseline SYNTAX score and rSS (ie, higher rSS in patients who had higher baseline SYNTAX scores), suggesting that it is difficult to obtain complete revascularization in patients with complex coronary disease undergoing PCI. Furthermore, they reported that rSS was a strong independent predictor of all ischemic outcomes at 1 year, including all-cause

Another interesting point raised by Mack and colleagues ${ }^{6}$ is that cardiologists and internists continue to recommend PCI to patients with complex multivessel coronary artery disease despite the data from SYNTAX and other trials. This raises the importance of having a multidisciplinary heart team, ${ }^{11}$ emphasized in both the American and European guidelines along with a recent systematic review. ${ }^{12-14}$

A key consideration is whether the benefit of CABG compared with PCI in patients with multivessel disease seen in SYNTAX is due to the inherent differences of these methods of revascularization. One of the putative mechanisms underlying the relative benefit of $\mathrm{CABG}$, along with the documented more complete revascularization, is that bypass can treat existing as well as future blockages. If the high rates of late fatal myocardial infarction with PCI are due to IR or new coronary lesions, then surgical revascularization should continue to be preferred in patients with multivessel disease. Alternatively, if late stent thrombosis is responsible for many of the late infarctions, the gap in results could be reduced with additional 
improvements in PCI-specifically fractional flow reserve $^{15}$ and later generation stents. ${ }^{16}$ Regardless, it behooves cardiac surgeons to adopt measures to reduce further the perioperative complications - in particular stroke ${ }^{17}$ and also late graft failure. To this end, there have been advances in off-pump techniques and, more recently, a push toward arterial revascularization. ${ }^{14,18-20}$ As well, it is important to emphasize that the results of both PCI and CABG are enhanced by optimal medical therapy and that continuous research and advances in pharmacotherapy are therefore paramount.

In conclusion, we agree with the excellent editorial by Mack and colleagues ${ }^{6}$ that patients with complex coronary disease should be offered CABG in preference to PCI, because there is a clear advantage with respect to cardiacrelated survival.

\section{References}

1. Serruys PW, Morice MC, Kappetein AP, Colombo A, Holmes DR, Mack MJ, et al; SYNTAX Investigators. Percutaneous coronary intervention versus coronary-artery bypass grafting for severe coronary artery disease. $N$ Engl J Med. 2009;360:961-72. Erratum in: N Engl J Med. February 7, 2013;368(6):584.

2. Mohr FW, Morice MC, Kappetein AP, Feldman TE, Ståhle E, Colombo A, et al. Coronary artery bypass graft surgery versus percutaneous coronary intervention in patients with three-vessel disease and left main coronary disease: 5-year follow-up of the randomised, clinical SYNTAX trial. Lancet. 2013;381:629-38.

3. Kappetein AP, Feldman TE, Mack MJ, Morice MC, Holmes DR, Ståhle E, et al. Comparison of coronary bypass surgery with drug-eluting stenting for the treatment of left main and/or three-vessel disease: 3-year follow-up of the SYNTAX trial. Eur Heart J. 2011;32:2125-34.

4. Kappetein AP, Head SJ, Morice MC, Banning AP, Serruys PW, Mohr FW, et al; SYNTAX Investigators. Treatment of complex coronary artery disease in patients with diabetes: 5-year results comparing outcomes of bypass surgery and percutaneous coronary intervention in the SYNTAX trial. Eur J Cardiothorac Surg. 2013;43:1006-13.

5. Milojevic M, Head SJ, Parasca CA, Serruys PW, Mohr FW, Morice MC, et al. Causes of death following PCI versus CABG in complex CAD: 5-year followup of SYNTAX. J Am Coll Cardiol. 2016;67:42-55.

6. Mack M, Baumgarten H, Lytle B. Why surgery won the SYNTAX trial and why it matters. J Thorac Cardiovasc Surg. 2016;152:1237-40.

7. Lehmann R, Fichtlscherer S, Schächinger V, Held L, Hobler C, Baier G, et al. Complete revascularization in patients undergoing multivessel PCI is an independent predictor of improved long-term survival. J Interv Cardiol. 2010;23: 256-63.

8. Mocanu V, Buth KJ, Kelly R, Légaré JF. Incomplete revascularization after coronary artery bypass graft operations is independently associated with worse long-term survival. Ann Thorac Surg. 2014;98:549-55.
9. Garcia S, Sandoval Y, Roukoz H, Adabag S, Canoniero M, Yannopoulos D, et al. Outcomes after complete versus incomplete revascularization of patients with multivessel coronary artery disease: a meta-analysis of 89,883 patients enrolled in randomized clinical trials and observational studies. J Am Coll Cardiol. 2013; 62:1421-31.

10. Généreux P, Palmerini T, Caixeta A, Rosner G, Green P, Dressler O, et al. Quantification and impact of untreated coronary artery disease after percutaneous coronary intervention: the residual SYNTAX (Synergy Between PCI With Taxus and Cardiac Surgery) score. J Am Coll Cardiol. 2012;59:2165-74.

11. Head SJ, Kaul S, Mack MJ, Serruys PW, Taggart DP, Holmes DR Jr, et al. The rationale for Heart Team decision-making for patients with stable, complex coronary artery disease. Eur Heart J. 2013;34:2510-8.

12. Fihn SD, Gardin JM, Abrams J, Berra K, Blankenship JC, Dallas AP, et al; American College of Cardiology Foundation/American Heart Association Task Force. 2012 ACCF/AHA/ACP/AATS/PCNA/SCAI/STS guideline for the diagnosis and management of patients with stable ischemic heart disease: a report of the American College of Cardiology Foundation/American Heart Association task force on practice guidelines, and the American College of Physicians, American Association for Thoracic Surgery, Preventive Cardiovascular Nurses Association, Society for Cardiovascular Angiography and Interventions, and Society of Thoracic Surgeons. Circulation. 2012;126:e354-471. Erratum in: Circulation. 2014;129:e463.

13. Task Force on Myocardial Revascularization of the European Society of Cardiology (ESC) and the European Association for Cardio-Thoracic Surgery (EACTS); European Association for Percutaneous Cardiovascular Interventions (EAPCI); Wijns W, Kolh P, Danchin N, Di Mario C, Falk V, Folliguet T, et al. Guidelines on myocardial revascularization. Eur Heart J. 2010;31:2501-55.

14. Deb S, Wijeysundera HC, Ko DT, Tsubota H, Hill S, Fremes SE. Coronary artery bypass graft surgery vs percutaneous interventions in coronary revascularization: a systematic review. JAMA. 2013;310:2086-95.

15. van Nunen LX, Zimmermann FM, Tonino PA, Barbato E, Baumbach A, Engstrøm T, et al; FAME Study Investigators. Fractional flow reserve versus angiography for guidance of PCI in patients with multivessel coronary artery disease (FAME): 5-year follow-up of a randomised controlled trial. Lancet. 2015; 386:1853-60.

16. Dangas GD, Serruys PW, Kereiakes DJ, Hermiller J, Rizvi A, Newman W, et al. Meta-analysis of everolimus-eluting versus paclitaxel-eluting stents in coronary artery disease: final 3-year results of the SPIRIT clinical trials program (Clinical Evaluation of the Xience V Everolimus Eluting Coronary Stent System in the Treatment of Patients With De Novo Native Coronary Artery Lesions). JACC Cardiovasc Interv. 2013;6:914-22.

17. Smit Y, Vlayen J, Koppenaal H, Eefting F, Kappetein AP, Mariani MA. Percutaneous coronary intervention versus coronary artery bypass grafting: a meta-analysis. J Thorac Cardiovasc Surg. 2015;149:831-8. e1-13.

18. Deb S, Cohen EA, Singh SK, Une D, Laupacis A, Fremes SE. RAPS Investigators. Radial artery and saphenous vein patency more than 5 years after coronary artery bypass surgery: results from RAPS (Radial Artery Patency Study). J Am Coll Cardiol. 2012;60:28-35.

19. Deb S, Fremes SE. Using bilateral internal thoracic arteries- - just do it. J Thorac Cardiovasc Surg. 2016;152:128-30.

20. Magruder JT, Young A, Grimm JC, Conte JV, Shah AS, Mandal K, et al. Bilateral internal thoracic artery grafting: does graft configuration affect outcome? J Thorac Cardiovasc Surg. 2016;152:120-7. 